\title{
Effectiveness study on applied quality assurance of ducational technology in learning quality improvement in universities
}

\author{
Haryono ", Titi Prihatin, Ghanis Putra Widhanarto \\ Universitas Negeri Semarang, Indonesia
}

\begin{abstract}
Educational technology is an applied scientific discipline that develops by the need of the field , namely the demands of learning more effectively, efficiently, broadly, widely, and quickly. As a systematic and systematic process in helping to solve learning problems, the application of educational technology can be directed to the learning quality assurance process. This study is aimed at: (1) analyzing the application of educational technology in improving the quality of learning in universities, (2) analyzing the quality assurance process of learning in universities, and (3) testing the effectiveness of quality assurance models based on applied educational technology in improving the quality of learning in College. The method used is a quantitative approach. The study began with an exploratory survey method, then continued with experiments. The results showed that the analysis of the quality of learning in universities was very dependent on the application of educational technology, the learning quality assurance process agreed that educational technology could improve the quality of learning in universities, and the application of quality assurance models based on applied learning technology is effective to improve the quality of learning in college high. The benefits of this study as a reference for the development model of quality assurance, especially for education and learning.
\end{abstract}

\section{Introduction}

Learning activity is the main of the educational process that takes place within each educational unit or institution. Professional educators are responsible for achieving quality learning through the creation of meaningful learning experiences for students, in addition for facilitating students to gain the maximum learning outcomes. Schools or education units are responsible for building a quality learning system so that they are able to contribute fully to the intellectual development, attitudes and morals of students in a complete harmonization (Haryono, 2016).

The quality of learning is needed to make an education that can create students in better learning capacity. Quality learning will lead students not only to acquire a number of knowledge, skills and attitudes, but more important is to develop their learning capacity on how to acquire knowledge, skills and attitude (Zamroni, 2000; Semiawan, 1998). Therefore the quality of learning is needed as a criterion dimension to be a benchmark for professional development of educators as well as the development of schools as educational institutions that must consistently develop towards competition in the information and openness era of the world.

Related to efforts to improve the quality of learning that must be sought by every professional educator, educational technology is present to provide enlightenment. Educational technology as an area of interest with an effort to facilitate the learning process with characteristics; (1) provide special attention and unique services from each of the target students, (2) use variety and as many learning resources as possible, and (3) apply a systems approach (Miarso, 2002). Educational technology is not just an application of technology products in education, but is a systematic and systemic process to enable a higher quality education and learning process. Although it is undeniable that in the system process it allows for the application of technology in the meaning of the product (Haryono, 2008).

Applied educational technology in the learning system, has the potential to improve the quality of learning that has an impact on the acquisition of student learning outcomes. Praxis of learning cannot be separated from the application of educational technology. Quality learning can only be realized, when properly designed, equipped with the necessary materials, presented through the media and the use of appropriate resources, the division of roles is clearly defined based on function, and properly assessed (Haryono, 2008). This prerequisite is a field of educational technology work both theoretically and practically.

Applied education technology functionally can be directed to the learning quality assurance process. Educational technology that is conceptually defined as study and ethical practice in facilitating learning and improving performance through the creation, utilization and management of appropriate technological processes and resources (Januszewski \& Molenda, 2008). The quality assurance process can be developed by basing and applying the basic principles of educational technology. Quality assurance of educational technology-based learning can be directed at efforts; (1) building a culture of quality among the components of the learning system in schools, (2) the division of tasks and responsibilities that are clear and proportional among the components of the learning system in schools, (3) the internal school setting starts about the quality standards of learning that are committed of all components in the learning system, and (4) the 
establishment of a learning quality information system in the education unit. Quality assurance of learning is developed with the principles of sustainable, planned and systematic with a clear and measurable time frame and quality achievement targets, respecting school autonomy, facilitating the achievement of quality learning, and improving the quality of education in a sustainable manner (Haryono, 2016).

\section{Methods}

Referring to the objectives to be achieved, this research program was designed with a quantitative approach with quasi-experimental and survey methods. The survey was conducted to examine the application of educational technology in improving the quality of learning and the quality assurance process of learning in universities, while the quasi-experimental method with pretest posttest control group design was conducted to test the effectiveness of educational technology-based quality assurance in improving the quality of learning. Technically the research method that will be conducted to answer research questions can be explained as follows.

In accordance with the objectives of the study and the characteristics of the data collected, the analysis is carried out descriptively and inferentially. Descriptive analysis was carried out to see trends in relation to the variables under study, while inferential analysis was carried out to test hypotheses regarding the effectiveness-based quality assurance of educational technologyin improving the quality of learning in universities.

\section{Results}

The applied model of quality assurance learning system in comprehensive education technology can be visualized in the flow chart as follows.

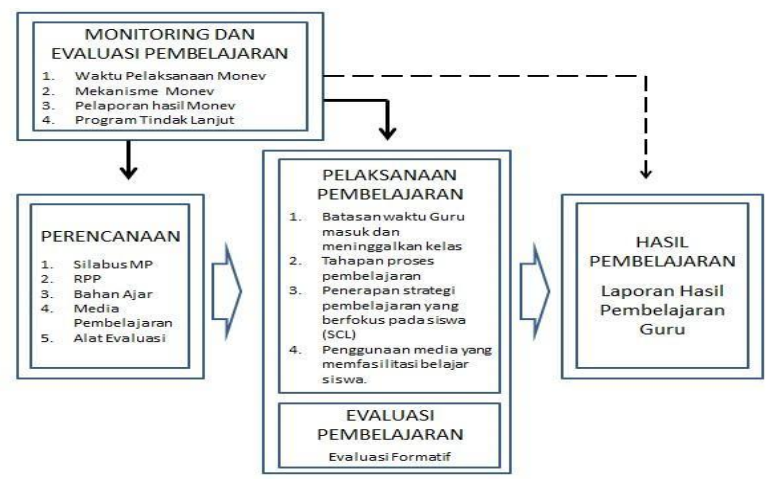

Fig 1. Quality Assurance Model for Applied Based LearningTechnology Education

The quality assurance model of education technology based learning as a process of monitoring and evaluating learning is carried out through three stages, namely learning planning, implementation of learning processes, monitoring and evaluation of learning. In the learning planning stage, the process of preparing Semester
Learning Plans (RPS), developing instructional materials, developing learning media, and measuring learning outcomes by lecturers is developed. The validation process of learning planning by the lecturer is done to get results in accordance with the established quality assurance standards.

The quality assurance stage is then carried out in the learning process. The implementation of learning quality assurance is carried out during the learning process where the quality assurance team validates whether the learning is carried out in accordance with the planning that was made in the previous stage. Furthermore, the monitoring and evaluation of the implementation of learning activities is carried out as the third or final stage in the quality assurance of learning based on applied educational technology.

Monitoring and evaluation is carried out by periodic monitoring and evaluation, namely the beginning of the semester, mid-semester, and the end of the semester. The results of monitoring and evaluation are then reported periodically in accordance with the monitoring and evaluation activities carried out. The results of the monitoring and evaluation were held by the stakeholders to conduct follow-up programs as an effort to improve the quality of learning quality, as well as a material of self-reflection for the improvement of further learning.

\subsection{Applied Educational Technology in Improving the Quality of Learning in Higher Education}

Revealing the application of educational technology in higher education there are results that state that there is still a lack of applied quality assurance models in learning. From the data taken shows the results that educational technology is applied to certain fields, namely:

1. Lecturer Competence in the Application of Educational Technology proven by teaching experience of less than 10 years stated that in higher education implemented educational technology but only a few respondents.

2. Implementation of Educational Technology in Praxis Learning shows very good results, the average lecturer with teaching experience under 10 years has implemented educational technology in the praxis of learning.

3. Impact of Application of Educational Technology in Achieving Learning Quality in Universities from research results stated that the high use of learning media, teaching materials, learning-specific services, electronic learning resources, and systems approaches to learning have been carried out but have not yet reached all parties.

\subsection{Quality Assurance Process of Learning in Higher Education}

Learning standards include, planning, implementing, monitoring and evaluating learning. There is evidence 
found that the standard of learning has been done very well.

The learning quality assurance mechanism starts with monitoring, the distribution of courses, RPS endorsement, and monev have been done well but only mostly.

Learning quality assurance instruments and instruments are proven by quality assurance response questionnaires, learning quality assurance standards, operational standards for developing instructional materials, operational standards for learning media development procedures, quality assessment matrices for learning in universities. So it was concluded that all parties had done it.

\subsection{The Effectiveness of Applied Quality Assurance Models Educational Technology in Improving the Quality of Learning in Higher Education}

1. appropriateness of the learning process standards is proven by the Lecturers validating the devices that contain preliminary activities, core activities and closing activities, the ability of the lecturer to speak (tone, intonation, expression) well, and able to listen, the ability of the lecturer to explain something abstract into something that is easy to understand, the ability of lecturers related to the visualization of ideas in the form of communicative presentation materials through various media and relevant technology tools. So that the learning process standard has been implemented very well.

2. Its usefulness for the development of quality culture in universities has increased the interaction of lecturers and students using technology, there has been an increase in the number of electronic teaching materials used in lectures, there has been an increase in the availability of technology support facilities provided by the campus. and the relevance of the material presented by the lecturer with the development of scientific discipline, and being able to take advantage of the results of related research.

\section{Discussion}

Learning is a systematic and deliberate effort to create educational interaction between students and learning resources, so that learning occurs in students. Learning is a deliberate effort, purposeful, controlled so that other people learn or occur changes that are relatively settled (Miarso, 2004).

Applied educational technology in the teaching and learning process at several universities in Central Java shows that good academic interaction has occurred. hasyim wahid university runs the application of educational technology Educational

technology as an applied discipline, developing by the need in the field, namely the need to learn more effectively, efficiently, widely, quickly, and so on. For that there is a product that is intentionally developed for the sake of learning, and there is something that is found and can be utilized for the same benefit. Educational technology is a systemic process in helping to solve human learning problems throughout life, anywhere, anytime, by any means, and by anyone (Miarso, 2004). Furthermore, referring to the definition of technology education is the study and ethical practice of facilitating and improving performance by creating, using, and managing appropriate technological processes and resources (Januszewski \& Molenda, 2008), educational technology can contribute theoretically and practically in improving the quality of learning.

Quality assurance of learning in universities is a strategic step in realizing standardized learning services and continuous quality improvement efforts. The learning quality assurance system is based on applied educational technology, based on the results of Haryono's research (2015-2016), in which it contains; (1) limitations and scope of quality assurance of learning in universities, (2) quality and organizational policies, (3) quality standards of learning and mechanisms for achievement, (4) manuals for quality learning and instruments.

\section{Conclusion}

The results showed that the analysis of the quality of learning in college depends on the application of educational technology, the learning quality assurance process agreed that educational technology can improve the quality of learning in universities, and the application of quality assurance models based on applied learning technology is effective to improve the quality of learning in College.

\section{References}

1. Haryono. 2008. "Applied Errors in Educational Technology in Praxis of Forgotten Learning". Speech inauguration of Professor of Unnes Education Technology. Semarang, February 26, 2008. Downloaded June 2017 from http://blog.unnes.ac.id/fransharyono.

2. Haryono, et al. 2016. "Implementation of Quality Assurance Based on Applied Educational Technology". Research Report (Unpublished). LP2M Unnes.

3. Januszewski, Alan and Michael Molenda. 2008. Educational Technology: A Definition with Commentary. New York: Taylor \& Francis Group.

4. Miarso, Yusufhadi. 2002. "Concepts and Applied Learning Technology", Paper in the First Lecture of TP S2 UNNES Students, September 14, 2002.

5. Semiawan, Conny R. 1998. Higher Education: Improving Human Ability as Optimum as possible. Jakarta: Directorate General of Higher Education Ministry of Education and Culture.

6. Zamroni. 2000. Educational Paradigm of the Future. Yogyakarta: Bigraf Publishing. 